\title{
Review \\ Developments in the scientific and clinical understanding of gout
} Alexander So

Service de Rhumatologie, Departement de Médecine, CHU Vaudois, University of Lausanne, Ave Pierre Decker, 1011 Lausanne, Switzerland

Corresponding author: Alexander So, alexanderkai-lik.so@chuv.ch

Published: 10 October 2008

This article is online at http://arthritis-research.com/content/10/5/221

(c) 2008 BioMed Central Ltd

Arthritis Research \& Therapy 2008, 10:221 (doi:10.1186/ar2509)

\begin{abstract}
Gout is the most common form of inflammatory arthritis in the elderly. In the last two decades, both hyperuricemia and gout have increased markedly and similar trends in the epidemiology of the metabolic syndrome have been observed. Recent studies provide new insights into the transporters that handle uric acid in the kidney as well as possible links between these transporters, hyperuricemia, and hypertension. The treatment of established hyperuricemia has also seen new developments. Febuxostat and PEGuricase are two novel treatments that have been evaluated and shown to be highly effective in the management of hyperuricemia, thus enlarging the therapeutic options available to lower uric acid levels. Monosodium urate (MSU) crystals are potent inducers of inflammation. Within the joint, they trigger a local inflammatory reaction, neutrophil recruitment, and the production of proinflammatory cytokines as well as other inflammatory mediators. Experimentally, the uptake of MSU crystals by monocytes involves interactions with components of the innate immune system, namely Toll-like receptor (TLR)-2, TLR-4, and CD14. Intracellularly, MSU crystals activate multiple processes that lead to the formation of the NALP-3 (NACHT, LRR, and pyrin domain-containing-3) inflammasome complex that in turn processes pro-interleukin (IL)-1 to yield mature IL-1 $\beta$, which is then secreted. The inflammatory effects of MSU are IL-1-dependent and can be blocked by IL-1 inhibitors. These advances in the understanding of hyperuricemia and gout provide new therapeutic targets for the future.
\end{abstract}

\section{Introduction}

Gout is an inflammatory process initiated by tissue deposition of monosodium urate (MSU) crystals. A typical attack is an acute monoarthritis accompanied by the classical signs of inflammation. However, inflammation can occur in any tissue in which MSU is deposited, as typified by tophaceous gout and by urate nephropathy due to renal medullary deposition of MSU crystals. Uric acid, a weak acid with a pK of 5.7, is the normal product of purine metabolism in humans and in the plasma exists mainly in the form of urate. In the more acidic environment of the renal tubule, however, it is found mainly in the form of uric acid. At physiological $\mathrm{pH}$, urate crystals form when the plasma solubility of uric acid is exceeded, whereas in the kidney tubule, uric acid crystals are formed when the saturation point of uric acid is exceeded. Hyperuricemia is the main factor that facilitates the formation of MSU crystals, although other factors (such as local temperature and trauma) may also play a role. Once formed, urate crystals are capable of provoking an inflammatory response from leukocytes and synovial cells to trigger the release of cytokines that amplify the local inflammatory reaction. This review will summarize recent progress in our understanding of uric acid metabolism in humans, in particular the role of renal transporters in regulating urate levels. The mechanisms through which MSU crystals cause inflammation have also been intensively studied and these insights are likely to affect our therapy of hyperuricemia and gout in the future.

\section{Epidemiology of hyperuricemia and gout}

Throughout the Western world, there is strong epidemiological evidence that the prevalence of gout and hyperuricemia is on the increase [1,2]. Based on data from an American insurance database, Wallace and colleagues [3] estimated that between the 1990 and 1999, the prevalence of gout increased by $60 \%$ in those over 65 years of age and doubled in the population over 75 years of age. In a study based on UK general practice data, the prevalence of gout in the adult population was estimated to be $1.4 \%$, with a peak of more than $7 \%$ in men over 75 years of age [1]. These figures suggest that gout is the most common form of inflammatory arthritis in adults and that it is on the increase. This trend not only was observed in Western populations but appears to affect developing countries in Asia [4,5]. Indeed, a strong association between hyperuricemia and the metabolic syndrome (the constellation of insulin resistance, hypertension, obesity, and dyslipidemia) has been observed in these countries, similar to findings in the West. Potential explana-

ASC = apoptosis-associated speck-like protein containing a caspase-associated recruitment domain; CARD = caspase-associated recruitment domain; CT = computed tomography; IL = interleukin; MRI = magnetic resonance imaging; MSU = monosodium urate; NALP-3 = NACHT, LRR, and pyrin domain-containing-3; NLR = Nod/NACHT-LRR domains; NSAID = nonsteroidal anti-inflammatory drug; TLR = Toll-like receptor; URAT-1 = urate transporter-1. 
tions for these findings include lifestyle and dietary changes brought about by increasing prosperity and increased life expectancy and age of the population.

\section{Uric acid metabolism}

Uric acid is the end result of the purine metabolic pathway and the product of the conversion of xanthine, by the action of xanthine oxidase, to uric acid. As uric acid is a weak acid, its main form in plasma is MSU, which has a maximum solubility of about $420 \mu \mathrm{mol} / \mathrm{L}(7 \mathrm{mg} / \mathrm{dL})$. Normal plasma urate levels are between 200 and $410 \mu \mathrm{mol} / \mathrm{L}$ (3.3 to $6.9 \mathrm{mg} / \mathrm{dL}$ ). Apart from higher primates, all mammals express uricase, an enzyme that converts uric acid to allantoin, and this explains why, in humans, urate levels are much higher than those of other mammals. The loss of a functional uricase gene in humans during evolution has been ascribed to the physiological advantages that higher levels of serum urate may have brought to hominid evolution, such as its potential effect on increasing blood pressure, its anti-oxidant properties, and its immunostimulatory properties [6].

The relationship between hyperuricemia, hypertension, and the metabolic syndrome has long been debated. Are the conditions different manifestations of a common underlying metabolic disorder? Is hyperuricemia in part responsible for hypertension? Recent evidence from animal studies and epidemiology would suggest that hyperuricemia has a primary role in both hypertension and the metabolic syndrome. Rats that were made hyperuricemic rapidly developed hypertension through activation of the renin-angiontensin system, induction of endothelial dysfunction, and vascular smooth muscle proliferation. Lowering uric acid in these animals prevented this effect [7]. In a longitudinal study in children, there was a strong correlation between hyperuricemia and the subsequent development of hypertension [8]. Recent epidemiological data suggest also that hyperuricemia is an independent risk factor for developing hypertension. In a group of subjects who did not have the metabolic syndrome, normotensive men with baseline hyperuricemia had an $80 \%$ excess risk for developing hypertension compared with those who did not have hyperuricemia [9]. Finally, the degree of hyperuricemia is strongly correlated with the prevalence of the metabolic syndrome $[5,10]$ and it has been suggested that excessive consumption of fructose may be the link between these two conditions [11].

\section{Renal transporters of uric acid}

About $90 \%$ of the daily load of urate filtered by the kidney is reabsorbed and this process is mediated by specific transporters. The major transporter is urate transporter-1 (URAT-1), a urate-anion exchanger localized on the luminal side of the proximal renal tubule. URAT-1 is part of the family of organic anion transporters and is the major mechanism for reabsorbtion of urate in the human kidney. Mutations of the URAT-1 gene give rise to hereditary renal hypouricemia, and URAT-1 transport of uric acid is inhibited by drugs such as benzbromarone and probenicid, explaining their uricosuric effect [12]. Other transporters that have been found to mediate urate excretion include NPT1 and MRP4, although their precise contribution to uric acid balance in vivo has yet to be established [13].

\section{Genetics of hyperuricemia}

The well-known monogenic causes of hyperuricemia, such as HGPRT (hypoxanthine-guanine phosphoribosyl transferase) deficiency and PRPP (phosphoribosylpyrophosphate) synthetase overactivity, account for but a small fraction of cases of hyperuricemia and gout. With the advent of large-scale genomics, genes that influence serum urate level in the general population are being discovered. To date, little is known about the genetic polymorphism of the urate transporters and whether they may contribute to hyperuricemia and gout. Two recent studies have suggested that polymorphisms or mutations of the URAT-1 gene are associated with hyperuricemia and gout $[14,15]$. Using a whole-genome approach to study the genetic influences on hyperuricemia, polymorphisms around the GLUT9 gene (SLC2A9) on chromosome $4 p 16$ were highly significantly linked with hyperuricemia and gout in several studies [16-18]. Variations in the gene were estimated to account for between 1.5\% and $5 \%$ of the population variance of serum uric acid concentration, with a higher value observed in females than males. GLUT9 was first identified as a glucose and fructose transporter that is expressed in the kidney and in leukocytes, but its precise role in urate metabolism remains to be defined. In in vitro studies, GLUT9 is a potent uric acid transporter and its renal expression suggests that it has a role in regulating renal urate excretion. A more targeted genetic approach has also been adopted to study genetic influences in subjects with hyperuricemia and gout. In a Taiwanese family study involving 64 pedigrees, genetic markers in the region of chromosome 1q21 segregated with hyperuricemia and gout [19]. As mentioned already, mutations in the URAT-1 gene have been linked to primary gout, and in a Mexican study, a surprisingly high proportion of patients (23\%) were found to carry mutations in the URAT-1 gene [15].

\section{How do monosodium urate crystals cause inflammation?}

The mechanisms by which MSU crystals elicit an inflammatory response in joints have begun to be unraveled. It has long been known that MSU crystals evoke an inflammatory infiltrate rich in neutrophils when injected into the peritoneum or in the air pouch in animal models. The capacity of MSU crystals to stimulate monocyte/macrophages and synoviocytes to release IL-1 $\beta$ was recognized more than 20 years ago [20]. Recently, Liu-Bryan and colleagues [21] and Scott and colleagues [22] analyzed the molecular interactions that mediate this effect and showed that the innate immune system plays a pivotal role. The innate immune system, as distinct from the adaptive immune system of $T$ and $B$ cells, comprises a range of receptors and soluble proteins that 


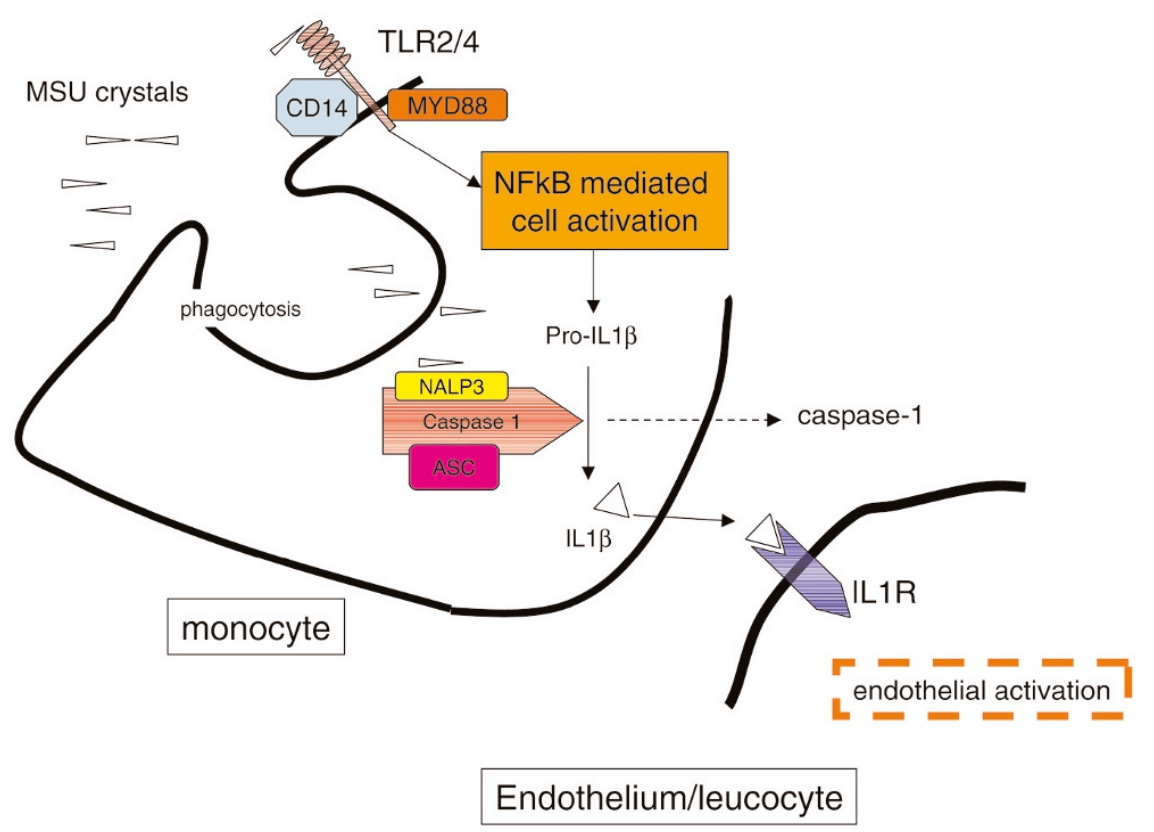

Monosodium urate (MSU) crystals activate monocytes via the Toll-like receptor (TLR) pathway and the inflammasome. Binding to TLR and CD14 promotes phagocytosis and cell activation through MYD88-dependent signalling mechanisms. In the cytosol, MSU crystals induce the formation of the NALP-3 (NACHT, LRR, and pyrin domain-containing-3) inflammasome and lead to caspase-1 processing of pro-IL-1 $\beta$. Activation of the endothelium by IL-1 $\beta$ increases trafficking of neutrophils to the inflammatory site. ASC, apoptosis-associated speck-like protein containing a caspase-associated recruitment domain; IL, interleukin; NF-KB, nuclear factor-kappa-B.

detect pathogens as well as cellular products released by damaged or dying cells through pattern recognition motifs. Binding to these innate immune receptors leads to cell activation, typically of phagocytic cells, as well as the release of cytokines and chemokines that orchestrate the initial inflammatory response. One family of innate immune receptors is that of the Toll-like receptors (TLRs). These molecules are transmembrane receptors that, on binding to extracellular ligands, trigger cellular activation and proliferation. Their roles in the recognition of pathogens and their intracellular signalling pathways have been studied in detail [23]. Murine bone marrow-derived macrophages that lack either TLR-2 or TLR-4 showed a reduced phagocytic capacity for MSU crystals, and the release of proinflammatory cytokines interleukin (IL)-1 $\beta$ and tumor necrosis factor-alpha by these cells was also diminished [21]. However, the role of TLRs may not be as critical in other cell types exposed to MSU crystals given that, in the peritoneal inflammation model, TLR-deficient mice did not show a major phenotype [24]. The second component is CD14, a pattern recognition molecule found on the cell surface and in the circulation which serves to amplify the cellular response triggered by TLR-2 and TLR-4 ligands such as lipopolysaccharide [25]. Mice that lack CD14 mounted no neutrophil response and produced significantly reduced amounts of IL-1 $\beta$ when MSU crystals were injected into an air pouch, although there was no reduction in their capacity to phagocytose crystals [22]. These experiments indicated that innate immune receptors and their associated signalling machinery are needed for MSU crystals to elicit an inflammatory response (Figure 1).

\section{Interleukin-1 $\beta$ and the inflammasome}

A recent discovery that has major implications in the pathogenesis and therapy of gout is the demonstration that MSU crystals are capable of triggering $\mathrm{IL}-1 \beta$ release by its interaction with a cytoplasmic complex called the 'inflammasome'. IL-1 $\beta$ is released extracellularly after enzymatic processing of its precursor molecule pro-IL-1 by caspase- 1 (or ICE, interleukin-converting enzyme). The activity of caspase- 1 is itself tightly regulated and requires the formation of homodimeric complexes of pro-caspase- 1 in the presence of the cytoplasmic protein ASC (apoptosis-associated specklike protein containing a caspase-associated recruitment domain [CARD]) and a protein of the NLR (Nod/NACHT-LRR domains) family. Because of its ability to initiate IL-1 $\beta$ processing and secretion, this molecular complex has been named the inflammasome. A number of different inflammasomes of differing compositions have been described [26]. One such NLR protein is NALP-3 (NACHT, LRR, and pyrin domain-containing-3), hence the NALP-3 inflammasome. NALP-3 is also termed cryopyrin as this protein is mutated in patients with hereditary autoinflammatory syndromes. This group of illnesses includes familial cold urticaria, Muckle- 
Wells syndrome, and CINCA (chronic infantile neurologic, cutaneous, and articular) and represents a continuum of clinical manifestations of inflammation in the skin, joint, and central nervous system. The identification of the NALP-3 mutations as well as the demonstration that, in patients with Muckle-Wells syndrome, IL- $1 \beta$ is produced spontaneously by monocytes point to IL-1 as a potential pathogenic molecule in this group of diseases [27]. This was confirmed in open clinical trials in which anakinra, an IL-1 inhibitor, had a rapid and dramatic effect on the symptoms and signs of inflammation [28]. When MSU crystals were added to monocytes in culture, both IL-1 $\beta$ and caspase- 1 were released into the supernatant, but this effect was completely suppressed in cells obtained from mice that had mutations in the ASC, NALP-3, or caspase-1 genes. Furthermore, in a murine model of gout in which MSU crystals were directly injected into the peritoneal cavity to elicit an inflammatory response, neutrophil influx was significantly reduced in ASC-deficient mice compared with wild-type mice [29]. Finally, mice that lacked IL-1R expression on non-bone marrow-derived cells were also protected from the inflammatory effects of MSU [24], suggesting that the pro-inflammatory effects of IL-1 require mesenchymal cells such as the endothelium to respond to this cytokine. Together, these findings strongly suggest that IL-1 is a pivotal mediator of inflammation in acute gout. Based on these results, an open clinical study was performed to assess whether the IL-1RA anakinra had a clinical effect in acute gout. In a small study of 10 patients, all patients responded rapidly and positively to three daily injections of anakinra [30]. These findings suggest that IL-1 $\beta$ is a target for treatment in acute gout which could complement existing therapies.

\section{Imaging in gout}

Traditionally, radiology has not been of primary importance in the diagnosis of gout as the appearance of erosions is a latestage finding. However, our therapeutic approach to hyperuricemia and gout could be modified if gouty tophi can be recognized earlier on in the disease. Gerster and colleagues [31] first described the characteristic appearances of gouty tophi visualized by computed tomography (CT), which on conventional radiology are not well seen at all. These tophaceous deposits were observed in the capsule, the synovium, as well as on articular cartilage and had a mean density of around 160 Hounsfield units. The size and volume of gouty erosions have also been quantified using CT [32], a technique that may prove to be useful in evaluating long-term treatment outcomes of hypouricemic drugs. The role of magnetic resonance imaging (MRI) and ultrasound imaging in gout has also been investigated. Both modalities were able to detect tophaceous deposits, although they do not appear to be as specific as CT [33]. As ultrasound is a relatively simple technique that can be used repeatedly with little risk, there is growing interest in its use to detect and measure gouty tophi in the hope that this will provide an objective assessment of tophus size and its change during treatment. Investigators have reported that intra-articular gouty deposits have a characteristic ultrasonographic appearance, distinguishable from that of pyrophosphate arthropathy [34,35]. In longer term studies, ultrasound also appeared to be sensitive to change of tophus size and correlated well with MRI imaging [36]. The clinical usefulness of ultrasonography in the diagnosis and management of gout, however, will need to be established in prospective long-term studies.

\section{Advances in therapy of hyperuricemia and gout}

The treatment of hyperuricemia and gout remains a challenge even though we appear to have a number of effective drugs. Many clinicians recognize that our existing treatment choices are often limited in the routine clinical setting. Allopurinol, the most commonly used drug to treat hyperuricemia, can provoke severe allergic-type reactions (for example, StevenJohnsons syndrome and toxic epidermolysis) and needs to be used with caution in renal failure. Fortunately, the incidence of these rare reactions is low, but skin rashes are frequently reported. A recent report from Taiwan indicated that severe skin reactions may have a genetic determinant located in the major histocompatibility complex [37]. One hundred percent of patients with severe reactions possessed the class I antigen HLA B58, whereas in the control population, the frequency of the antigen was 15\% [37]. Benzbromarone, a very effective uricosuric drug, was recently withdrawn from general distribution because of a number of cases of hepatic failure associated with its use. Other hypouricemic drugs are therefore needed. Recently, a new xanthine oxidase inhibitor, febuxostat, underwent clinical trials and was shown to be as effective as allopurinol in reducing hyperuricemia [38,39]. Febuxostat, unlike allopurinol, is not a purine analog and does not cross-react with allopurinol. In clinical trials, when administered at a daily dose of either 80 or $120 \mathrm{mg}$, it was more effective than a 300-mg daily dose of allopurinol in achieving the target value of uricemia (less than $6 \mathrm{mg} / \mathrm{dL}$ or less than $360 \mu \mathrm{mol} / \mathrm{L})$, a target that has been recommended in treatment guidelines for gout and hyperuricemia [40]. The side effect profile did not show major signals. After 1 year of treatment, it was as effective as allopurinol in controlling gout flares. However, the use of febuxostat was associated with a higher frequency of gout flares in the first 6 months of therapy (when compared with allopurinol) and highlights the importance of prescribing an effective prophylactic therapy to prevent gout flares at the initiation of any hypouricemic therapy. As of this writing, febuxostat has been approved for prescription in the European Union in the treatment of gout and still awaits approval by the US Food and Drug Administration. An alternative approach to reduce hyperuricemia is the use of uricase, which breaks uric acid down to allantoin, either in the form of rasburicase or in a PEGylated form. Both forms of uricase reduced serum urate levels rapidly in clinical trials [41-44], but the need for parenteral administration and the development of anti-uricase antibodies (at least in the case of rasburicase) would probably limit its use to selected cases in clinical practice. 
Both febuxostat and uricase increase the range of treatment options available to patients who are intolerant to allopurinol and uricosuric agents. The other major therapeutic target is the inflammatory sequelae of gout. Our current choices include nonsteroidal anti-inflammatory drugs (NSAIDs), colchicines, and corticosteroids. The efficacy of a short course of corticosteroids in acute gout has been empirically recognized by clinicians, and a recent trial confirmed that $35 \mathrm{mg}$ of prednisolone is equally as effective as $1,000 \mathrm{mg}$ of naproxen in the treatment of acute gout in patients in a primary care setting [45]. However, each class of drug is associated with known pharmacological side effects, and in elderly patients who present co-morbid medical conditions, their use may induce renal, gastrointestinal, or metabolic complications. This is potently illustrated in a study of the management of acute gout in the emergency room setting, which compared the use of NSAIDs (in the form of indomethacin) with oral glucocorticoids. The results showed that the two treatments were equally effective in controlling the symptoms of acute gout, but indomethacin was associated with significantly greater toxicity than a short course of oral steroids, mainly because of the gastrointestinal side effects of the former [46]. The knowledge that IL-1 $\beta$ is an important mediator of the inflammatory symptoms and signs of gout may lead to new treatment strategies that inhibit the release or the action of this cytokine. For the time being, however, the effectiveness of such an approach needs to be demonstrated in clinical trials before it can be recommended for routine use.

\section{Conclusion}

Recent advances in the pathophysiology of hyperuricemia and the renal handling of uric acid have suggested new therapeutic targets for drug development for treatment of hyperuricemia. In acute gout, the understanding of how MSU crystals trigger the inflammatory response indicates that IL-1 $\beta$ may be a new target for acute gout therapy. Both advances indicate that new treatments may soon emerge for this ancient and still common disease.

\section{The Scientific Basis
of Rheumatology:
A Decade of Progress}

This article is part of a special collection of reviews, The Scientific Basis of Rheumatology: A Decade of Progress, published to mark Arthritis Research \& Therapy's 10th anniversary.

Other articles in this series can be found at: http://arthritis-research.com/sbr

\section{Competing interests}

The author declares that he has no competing interests.

\section{References}

1. Mikuls TR, Farrar JT, Bilker WB, Fernandes S, Schumacher HR Jr., Saag KG: Gout epidemiology: results from the UK General Practice Research Database, 1990-1999. Ann Rheum Dis 2005, 64:267-272.

2. Mikuls TR, Saag KG: New insights into gout epidemiology. Curr Opin Rheumatol 2006, 18:199-203.

3. Wallace KL, Riedel AA, Joseph-Ridge N, Wortmann R: Increasing prevalence of gout and hyperuricemia over 10 years among older adults in a managed care population. J Rheumatol 2004, 31:1582-1587.

4. Lin SD, Tsai DH, Hsu SR: Association between serum uric acid level and components of the metabolic syndrome. J Chin Med Assoc 2006, 69:512-516.

5. Yoo TW, Sung KC, Shin HS, Kim BJ, Kim BS, Kang JH, Lee MH, Park JR, Kim H, Rhee EJ, Lee WY, Kim SW, Ryu SH, Keum DG: Relationship between serum uric acid concentration and insulin resistance and metabolic syndrome. Circ J 2005, 69: 928-933.

6. Shi Y, Evans JE, Rock KL: Molecular identification of a danger signal that alerts the immune system to dying cells. Nature 2003, 425:516-521.

7. Johnson RJ, Segal MS, Srinivas T, Ejaz A, Mu W, Roncal C Sánchez-Lozada LG, Gersch M, Rodriguez-lturbe B, Kang DH, Acosta JH: Essential hypertension, progressive renal disease, and uric acid: a pathogenetic link? J Am Soc Nephrol 2005, 16: 1909-1919.

8. Feig DI, Kang DH, Nakagawa T, Mazzali M, Johnson RJ: Uric acid and hypertension. Curr Hypertens Rep 2006, 8:111-115.

9. Krishnan E, Kwoh CK, Schumacher HR, Kuller L: Hyperuricemia and incidence of hypertension among men without metabolic syndrome. Hypertension 2007, 49:298-303.

10. Choi HK, Ford ES: Prevalence of the metabolic syndrome in individuals with hyperuricemia. Am J Med 2007, 120:442-447.

11. Nakagawa T, Tuttle KR, Short RA, Johnson RJ: Hypothesis: fructose-induced hyperuricemia as a causal mechanism for the epidemic of the metabolic syndrome. Nat Clin Pract Nephrol 2005, 1:80-86.

12. Enomoto $A$, Endou $\mathrm{H}$ : Roles of organic anion transporters (OATs) and a urate transporter (URAT1) in the pathophysiology of human disease. Clin Exp Nephrol 2005, 9:195-205.

13. Anzai $N$, Kanai $Y$, Endou $H$ : New insights into renal transport of urate. Curr Opin Rheumatol 2007, 19:151-157.

14. Shima $Y$, Teruya $\mathrm{K}$, Ohta $\mathrm{H}$ : Association between intronic SNP in urate-anion exchanger gene, SLC22A12, and serum uric acid levels in Japanese. Life Sci 2006, 79:2234-2237.

15. Vazquez-Mellado J, Jimenez-Vaca AL, Cuevas-Covarrubias S, Alvarado-Romano V, Pozo-Molina G, Burgos-Vargas R: Molecular analysis of the SLC22A12 (URAT1) gene in patients with primary gout. Rheumatology (Oxford) 2007, 46:215-219.

16. Vitart V, Rudan I, Hayward C, Gray NK, Floyd J, Palmer CN, Knott SA, Kolcic I, Polasek O, Graessler J, Wilson JF, Marinaki A, Riches PL, Shu X, Janicijevic B, Smolej-Narancic N, Gorgoni B, Morgan J, Campbell S, Biloglav Z, Barac-Lauc L, Pericic M, Klaric IM, Zgaga L, Skaric-Juric T, Wild SH, Richardson WA, Hohenstein $P$, Kimber CH, Tenesa A, et al:: SLC2A9 is a newly identified urate transporter influencing serum urate concentration, urate excretion and gout. Nat Genet 2008, 40:437-442.

17. Döring A, Gieger C, Mehta D, Gohlke H, Prokisch H, Coassin S, Fischer G, Henke K, Klopp N, Kronenberg F, Paulweber B, Pfeufer A, Rosskopf D, Völzke H, Illig T, Meitinger T, Wichmann HE, Meisinger C: SLC2A9 influences uric acid concentrations with pronounced sex-specific effects. Nat Genet 2008, 40:430-436.

18. Li S, Sanna S, Maschio A, Busonero F, Usala G, Mulas A, Lai S, Dei M, Orrù M, Albai G, Bandinelli S, Schlessinger D, Lakatta E, Scuteri A, Najjar SS, Guralnik J, Naitza S, Crisponi L, Cao A, Abecasis G, Ferrucci L, Uda M, Chen WM, Nagaraja R: The GLUT9 gene is associated with serum uric acid levels in Sardinia and Chianti cohorts. PLoS Genet 2007, 3:e194.

19. Wang WH, Chang SJ, Wang TN, Cheng LS, Feng YP, Chen CJ, Huang $\mathrm{CH}$, Ko YC: Complex segregation and linkage analysis of familial gout in Taiwanese aborigines. Arthritis Rheum 2004, 50:242-246. 
20. Di Giovine FS, Malawista SE, Nuki G, Duff GW: Interleukin 1 (IL 1) as a mediator of crystal arthritis. Stimulation of $T$ cell and synovial fibroblast mitogenesis by urate crystalinduced IL 1. J Immunol 1987, 138:3213-3218.

21. Liu-Bryan R, Scott P, Sydlaske A, Rose DM, Terkeltaub R: Innate immunity conferred by Toll-like receptors 2 and 4 and myeloid differentiation factor $\mathbf{8 8}$ expression is pivotal to monosodium urate monohydrate crystal-induced inflammation. Arthritis Rheum 2005, 52:2936-2946.

22. Scott $P, M a H$, Viriyakosol S, Terkeltaub R, Liu-Bryan R: Engagement of CD14 mediates the inflammatory potential of monosodium urate crystals. J Immuno/ 2006, 177:6370-6378.

23. Akira S, Takeda K: Toll-like receptor signalling. Nat Rev Immunol 2004, 4:499-511.

24. Chen CJ, Shi Y, Hearn A, Fitzgerald K, Golenbock D, Reed G, Akira S, Rock KL: MyD88-dependent IL-1 receptor signaling is essential for gouty inflammation stimulated by monosodium urate crystals. J Clin Invest 2006, 116:2262-2271.

25. Fujihara M, Muroi M, Tanamoto K, Suzuki T, Azuma $\mathrm{H}$, lkeda $\mathrm{H}$ : Molecular mechanisms of macrophage activation and deactivation by lipopolysaccharide: roles of the receptor complex. Pharmacol Ther 2003, 100:171-194.

26. Petrilli V, Dostert C, Muruve DA, Tschopp J: The inflammasome: a danger sensing complex triggering innate immunity. Curr Opin Immunol 2007, 19:615-622.

27. Agostini L, Martinon F, Burns K, McDermott MF, Hawkins PN, Tschopp J: NALP3 forms an IL-1beta-processing inflammasome with increased activity in Muckle-Wells autoinflammatory disorder. Immunity 2004, 20:319-325.

28. Hawkins PN, Lachmann HJ, Aganna E, McDermott MF: Spectrum of clinical features in Muckle-Wells syndrome and response to anakinra. Arthritis Rheum 2004, 50:607-612.

29. Martinon F, Petrilli V, Mayor A, Tardivel A, Tschopp J: Gout-associated uric acid crystals activate the NALP3 inflammasome. Nature 2006, 440:237-241.

30. So A, Desmedt T, Revaz S, Tschopp J: A pilot study of IL-1 inhibition by anakinra in acute gout. Arthritis Res Ther 2007, 9: R28.

31. Gerster JC, Landry M, Duvoisin B, Rappoport G: Computed tomography of the knee joint as an indicator of intraarticular tophi in gout. Arthritis Rheum 1996, 39:1406-1409.

32. Dalbeth N, Clark B, Gregory K, Gamble GD, Doyle A, McQueen FM: Computed tomography measurement of tophus volume: comparison with physical measurement. Arthritis Rheum 2007, 57:461-465.

33. Gerster JC, Landry M, Dufresne L, Meuwly JY: Imaging of tophaceous gout: computed tomography provides specific images compared with magnetic resonance imaging and ultrasonography. Ann Rheum Dis 2002, 61:52-54.

34. Grassi W, Meenagh G, Pascual E, Filippucci E: "Crystal clear"sonographic assessment of gout and calcium pyrophosphate deposition disease. Semin Arthritis Rheum 2006, 36:197-202.

35. Thiele RG, Schlesinger N: Diagnosis of gout by ultrasound. Rheumatology (Oxford) 2007, 46:1116-1121.

36. Perez-Ruiz F, Martin I, Canteli B: Ultrasonographic measurement of tophi as an outcome measure for chronic gout. $J$ Rheumatol 2007, 34:1888-1893.

37. Hung SI, Chung WH, Liou LB, Chu CC, Lin M, Huang HP, Lin YL, Lan JL, Yang LC, Hong HS, Chen MJ, Lai PC, Wu MS, Chu CY, Wang $\mathrm{KH}$, Chen $\mathrm{CH}$, Fann CS, Wu JY, Chen YT: HLA-B*5801 allele as a genetic marker for severe cutaneous adverse reactions caused by allopurinol. Proc Natl Acad Sci U S A 2005, 102:4134-4139.

38. Becker MA, Schumacher HR Jr., Wortmann RL, MacDonald PA Eustace D, Palo WA, Streit J, Joseph-Ridge N: Febuxostat compared with allopurinol in patients with hyperuricemia and gout. N Engl J Med 2005, 353:2450-2461.

39. Becker MA, Schumacher HR Jr., Wortmann RL, MacDonald PA, Palo WA, Eustace D, Vernillet L, Joseph-Ridge N: Febuxostat, a novel nonpurine selective inhibitor of xanthine oxidase: a twenty-eight-day, multicenter, phase II, randomized, doubleblind, placebocontrolled, dose-response clinical trial examining safety and efficacy in patients with gout. Arthritis Rheum 2005, 52:916-923.

40. Zhang W, Doherty M, Bardin T, Pascual E, Barskova V, Conaghan P, Gerster J, Jacobs J, Leeb B, Lioté F, McCarthy G, Netter P, Nuki G, Perez-Ruiz F, Pignone A, Pimentão J, Punzi L, Roddy E,
Uhlig T, Zimmermann-Gòrska I; EULAR Standing Committee for International Clinical Studies Including Therapeutics: EULAR evidence based recommendations for gout. Part II: Management. Report of a task force of the EULAR Standing Committee for International Clinical Studies Including Therapeutics (ESCISIT). Ann Rheum Dis 2006, 65:1312-1324.

41. Richette P, Briere C, Hoenen-Clavert V, Loeuille D, Bardin T: Rasburicase for tophaceous gout not treatable with allopurinol: an exploratory study. J Rheumato/ 2007, 34:2093-2098.

42. Sundy JS, Ganson NJ, Kelly SJ, Scarlett EL, Rehrig CD, Huang W, Hershfield MS: Pharmacokinetics and pharmacodynamics of intravenous PEGylated recombinant mammalian urate oxidase in patients with refractory gout. Arthritis Rheum 2007, 56:1021-1028.

43. Ganson NJ, Kelly SJ, Scarlett E, Sundy JS, Hershfield MS: Control of hyperuricemia in subjects with refractory gout, and induction of antibody against poly(ethylene glycol) (PEG), in a phase I trial of subcutaneous PEGylated urate oxidase. Arthritis Res Ther 2006, 8:R12.

44. De Angelis S, Noce A, Di Renzo L, Cianci R, Naticchia A, Giarrizzo GF, Giordano F, Tozzo C, Splendiani G, De Lorenzo A: Is rasburicase an effective alternative to allopurinol for management of hyperuricemia in renal failure patients? A double blind randomized study. Eur Rev Med Pharmacol Sci 2007, 11: 179-184.

45. Janssens $H J$, Janssen $M$, van de Lisdonk $E H$, van Riel $P L$, van Weel C: Use of oral prednisolone or naproxen for the treatment of gout arthritis: a double-blind, randomized equivalence trial. Lancet 2008, 371:1854-1860.

46. Man CY, Cheung IT, Cameron PA, Rainer TH: Comparison of oral prednisolone/paracetamol and oral indomethacin/paracetamol combination therapy in the treatment of acute goutlike arthritis: a double-blind, randomized, controlled trial. Ann Emerg Med 2007, 49:670-677. 